\title{
Autism spectrum disorder: prospects for treatment using gene therapy
}

\author{
Matthew Benger ${ }^{1}$, Maria Kinali ${ }^{2}$ and Nicholas D. Mazarakis ${ }^{1 *}$ (D)
}

\begin{abstract}
Autism spectrum disorder (ASD) is characterised by the concomitant occurrence of impaired social interaction; restricted, perseverative and stereotypical behaviour; and abnormal communication skills. Recent epidemiological studies have reported a dramatic increase in the prevalence of ASD with as many as 1 in every 59 children being diagnosed with ASD. The fact that ASD appears to be principally genetically driven, and may be reversible postnatally, has raised the exciting possibility of using gene therapy as a disease-modifying treatment. Such therapies have already started to seriously impact on human disease and particularly monogenic disorders (e.g. metachromatic leukodystrophy, SMA type 1). In regard to ASD, technical advances in both our capacity to model the disorder in animals and also our ability to deliver genes to the central nervous system (CNS) have led to the first preclinical studies in monogenic ASD, involving both gene replacement and silencing. Furthermore, our increasing awareness and understanding of common dysregulated pathways in ASD have broadened gene therapy's potential scope to include various polygenic ASDs. As this review highlights, despite a number of outstanding challenges, gene therapy has excellent potential to address cognitive dysfunction in ASD.
\end{abstract}

Keywords: Autistic spectrum disorder, Synaptic dysfunction, ASD models, Gene therapy, Viral vector

\section{Background}

"Between stimulus and response there is a space. In that space is our power to choose our response. In our response lies our growth and our freedom"-Viktor E Frankl.

In autism spectrum disorder (ASD), a neurodevelopmental disorder affecting $\sim 1.5 \%$ of the population [1], aetiologically diverse deficits in cognitive plasticity lead to broad impairments in communication and restricted, repetitive behaviours [2]. Comorbidities are common ( $~ 70 \%$ of cases) and include epilepsy; attention, mood and language disorders; sleep disturbance; gastrointestinal problems; and intellectual disability [3].

Despite the great personal and sociological cost of ASD (estimated to be $\$ 2$ million/patient/year [4]), only the antipsychotics risperidone and aripiprazole are currently FDA-approved to treat ASD, indicated solely in the treatment of irritability symptoms [5]. A fundamental reason for this lack of disease-modifying therapies

\footnotetext{
* Correspondence: n.mazarakis@imperial.ac.uk

${ }^{1}$ Gene Therapy, Centre for Neuroinflammation and Neurodegeneration, Division of Brain Sciences, Faculty of Medicine, Imperial College London, Hammersmith Hospital Campus, W12 0NN, London, UK

Full list of author information is available at the end of the article
}

may relate to ASD's pathogenesis, which appears to be principally driven by heterogeneous genetic mutations and variants and modulated by diverse gene $x$ environment interactions, to include pregnancy-related factors (e.g. maternal immune activation, maternal toxins) and perinatal trauma [2, 6-10]. Many of the encoded proteins implicated in ASD pathogenesis-such as cytoskeletal proteins, cell adhesion molecules and DNA-binding proteins-may be 'undruggable' using conventional small molecule drugs, which principally only modulate the function of receptors and enzymes [11].

In contrast, gene therapy-broadly defined as the delivery of nucleic acid polymers into cells to treat disease - may be used to repair, replace, augment or silence essentially any gene of interest in a target cell, opening up new areas of the proteome for drug targeting [12]. Other advantages of gene therapy versus small molecules include the ability to effect long-lasting clinical benefit with a single treatment and the potential to control cellular targeting via vector modifications [13].

Indeed, gene therapy is already making a clinical impact in the field of neurology, with Nusinersen, an

(C) The Author(s). 2018 Open Access This article is distributed under the terms of the Creative Commons Attribution 4.0 International License (http://creativecommons.org/licenses/by/4.0/), which permits unrestricted use, distribution, and reproduction in any medium, provided you give appropriate credit to the original author(s) and the source, provide a link to the Creative Commons license, and indicate if changes were made. The Creative Commons Public Domain Dedication waiver (http://creativecommons.org/publicdomain/zero/1.0/) applies to the data made available in this article, unless otherwise stated. 
antisense oligonucleotide therapy approved in Spinal muscular atrophy (SMA), and more recently Luxturna, a viral-based gene replacement strategy approved in Leber's congenital amaurosis, acting as the first disease-modifying therapies in both of these diseases $[14,15]$. In addition, a clinical trial in SMA by AveXis using systemic delivery of recombinant adeno-associated virus 9 (rAAV9) carrying a replacement SMN1 gene recently proved safe and efficacious in neonates [16]. On the other hand, gene therapies are clearly expensive in the short-term, with current therapies costing at least $\$ 500,000$ per treatment, and thus remaining unaffordable in many healthcare systems (see ref [17] for a thorough economic analysis).

This review will highlight key targets for ASD gene therapy, the utility of ASD models, and recent advances in our ability to deliver such therapies to the central nervous system (CNS). It will then move on to discuss recent gene therapy strategies in ASD, concentrating on conditions with available preclinical data, and the roadblocks facing their clinical translation.

\section{Genetic targets in ASD}

ASD may be divided into conditions driven by a single genetic defect (monogenic ASD) and conditions driven by multiple genetic defects (polygenic ASD). Monogenic ASD conditions often contain a variable cluster of phenotypes which include autism as part of a syndrome [18]. Whilst only accounting for $\sim 5 \%$ of ASD cases [18], such disorders are prime candidates for gene therapy for two major reasons: firstly, they lend themselves to developing genetic models of ASD, which enable elucidation of the genotype to phenotype pathway, the potential for disease reversibility postnatally, and the efficacy/toxicity of novel therapeutics; secondly, correction of a single causative protein defect has the potential to arrest and possibly reverse disease pathology. Indeed, a basis for preclinical gene therapy studies in ASD was founded by identification of the nature and function of causative genes for a number of monogenic conditions with autistic features, including Rett syndrome (RS), fragile X syndrome (FXS), Angelman syndrome (AS) and tuberous sclerosis (TSC) [19-23] (Table 1).

More recently, our understanding of the genetic landscape of ASD has been revolutionised by several whole-exome and whole-genome sequencing studies, identifying hundreds of de novo and rare inherited variants influencing sporadic ASD risk [24-32]. Many of these genes appear to be involved, either directly or indirectly, in synaptic morphology and activity, leading to the concept of ASD as a 'synaptopathy' [33, 34] (Fig. 1). Certainly, the idea of using gene therapy to increase or decrease the expression of target proteins within this network and 'retune' the synapse is a powerful one, which may be applicable to certain ASD cases.

However, in such a heterogeneous condition as ASD, it is important not to become evangelical about a single causative mechanism, especially given recent insights into the apparently critical roles of immune dysfunction and epigenetics in at least certain ASD cases [35, 36]. Furthermore, recent phase II clinical trials which looked to regulate synaptic function via GABA and glutamate receptor modulation failed to demonstrate significant overall benefit, despite strongly positive responses in certain patients $[37,38]$. Thus, it is important to consider whether targeting the synapse using gene therapy may be most appropriate for correcting particular ASD endophenotypes in specific patient subsets, rather than seeing it as a panacea for ASD, a topic that is returned to later in this article.

Table 1 Genotypic and phenotypic characteristics of monogenic conditions with ASD features

\begin{tabular}{|c|c|c|c|c|c|}
\hline $\begin{array}{l}\text { Monogenic } \\
\text { ASD }\end{array}$ & $\begin{array}{l}\text { Mutated } \\
\text { gene }\end{array}$ & Chromosome & Protein function & $\begin{array}{l}\text { Autism } \\
\text { prevalence }\end{array}$ & Other characteristics \\
\hline $\begin{array}{l}\text { Fragile } X \\
\text { syndrome }\end{array}$ & $\begin{array}{l}\text { FMR1 } \\
\text { (encodes } \\
\text { FMRP) }\end{array}$ & $x$ & $\begin{array}{l}\text { Binds and transports specific } \\
\text { mRNAs from the nucleus to } \\
\text { the ribosome [123] }\end{array}$ & $\begin{array}{l}\sim 30 \% \\
{[124]}\end{array}$ & $\begin{array}{l}\text { Long/narrow face, macroorchidism, long ears and p } \\
\text { hiltrum, mild to moderate intellectual disability, } \\
\text { hyperactivity, intellectual disability (ID), seizures }\end{array}$ \\
\hline $\begin{array}{l}\text { Rett } \\
\text { syndrome }\end{array}$ & MECP2 & $x$ & Chromatin modification [125] & $\begin{array}{l}\sim 60 \% \\
{[124]}\end{array}$ & $\begin{array}{l}\text { Microcephaly, breathing irregularities, language deficits, } \\
\text { repetitive/stereotyped hand movements, epilepsy, ID }\end{array}$ \\
\hline $\begin{array}{l}\text { MECP2 } \\
\text { duplication } \\
\text { syndrome }\end{array}$ & MECP2 & $x$ & Chromatin modification [125] & $\begin{array}{l}\sim 100 \% \\
{[126]}\end{array}$ & $\begin{array}{l}\text { Brachycephaly, spasticity, recurrent respiratory infections, } \\
\text { gastrointestinal hypermotility, genitourinary abnormalities, } \\
\text { epilepsy, ID }\end{array}$ \\
\hline $\begin{array}{l}\text { Tuberous } \\
\text { sclerosis }\end{array}$ & $\begin{array}{l}\text { TSC1 } \\
\text { TSC2 }\end{array}$ & $\begin{array}{l}9 \\
16\end{array}$ & $\begin{array}{l}\text { Inhibition of translation via mTORC1 } \\
\text { inhibition [127] }\end{array}$ & $\begin{array}{l}\sim 50 \% \\
{[124]}\end{array}$ & Benign tumours in multiple organs, epilepsy \\
\hline $\begin{array}{l}\text { Angelman } \\
\text { syndrome }\end{array}$ & UBE3A & 15 & $\begin{array}{l}\text { Targeting of proteins for } \\
\text { destruction via ubiquitin-tagging [41] }\end{array}$ & $\begin{array}{l}\sim 30 \% \\
{[124]}\end{array}$ & $\begin{array}{l}\text { Cheerful demeanour, microcephaly, epilepsy, } \\
\text { speech deficits, sleep disturbance, epilepsy, ID }\end{array}$ \\
\hline
\end{tabular}

Abbreviations: FMR1 fragile $\mathrm{X}$ mental retardation 1, FMRP fragile $\mathrm{X}$ mental retardation protein, MECP2 methyl-CpG-binding protein 2, TSC1 tuberous sclerosis 1, TSC2 tuberous sclerosis 2, UBE3A ubiquitin-protein ligase E3A 


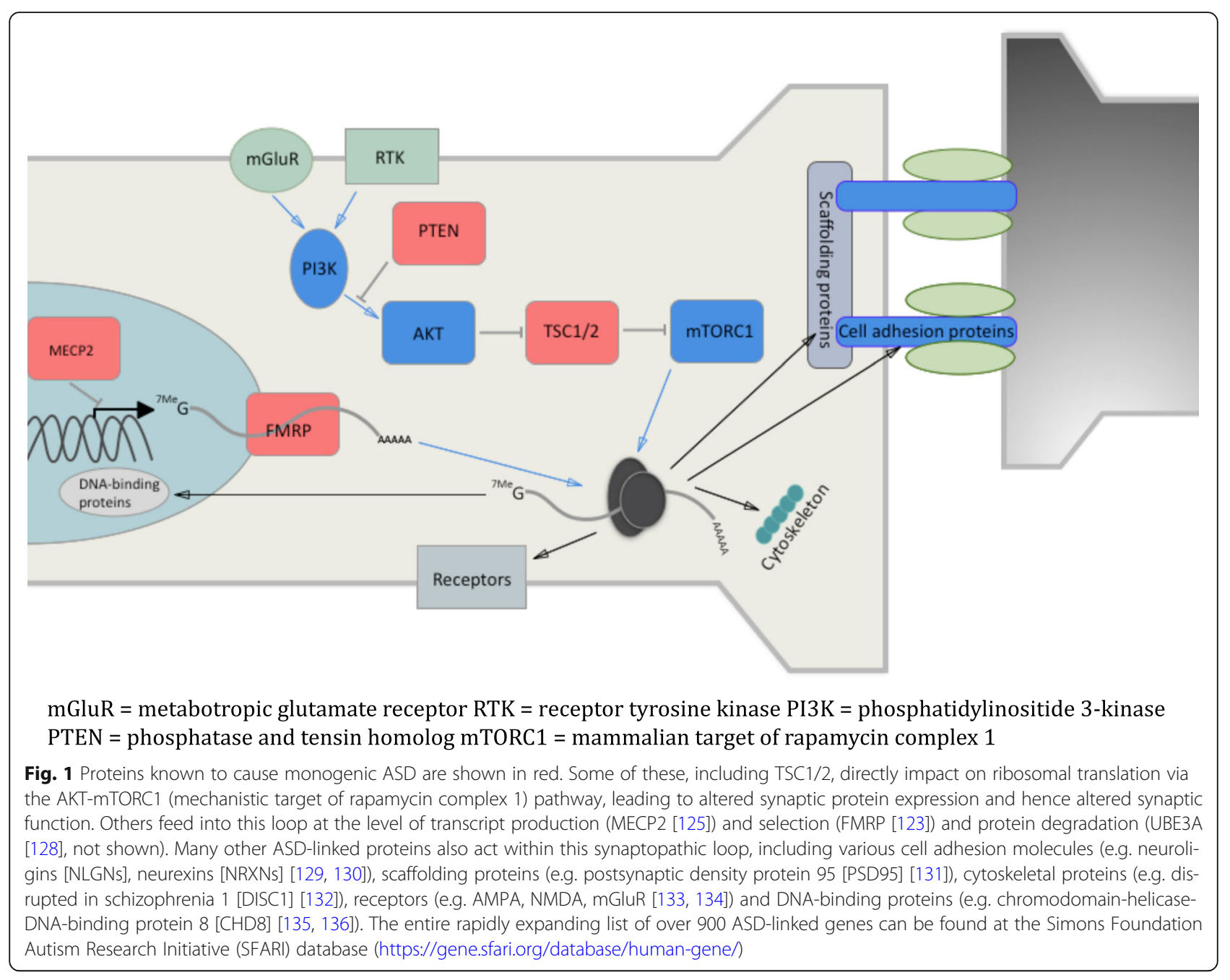

\section{Modelling ASD in rodents: a platform for proof- of-principle studies}

The field of gene therapy is littered with examples of therapies which failed to translate from their preclinical promise. In many cases, blame can be attributed to the predictive validity of the animal model used, which is itself related to its construct validity (i.e. how well the model mimics disease aetiology) and face validity (i.e. how closely the model's phenotype represents the human disorder) [39].

Given the challenges clinicians have faced in developing diagnostic criteria for ASD [40], and how various social traits often appear to be inherently 'human' qualities (although this is itself highly contested [41]), it is little wonder that generating ASD animal models with good face validity has been challenging. Nevertheless, whilst caution should always be taken when ascribing behavioural outcomes in animals to autism, various monogenic ASD rodent models have capably demonstrated quantifiable social and communicative behavioural traits [42-44], laying the ground for preclinical therapeutic studies.
As a caveat, it must be noted that a major limitation of ASD animal models relates to their inability to reflect heterogeneous environmental influences on the ASD phenotype, with various toxic, inflammatory and psychosocial factors difficult to incorporate in robust, reproducible animal models. This deficit in construct validity is especially relevant in modelling polygenic ASD, in which the gene $x$ environment interaction plays a more fundamental role [45], and which therefore bears a particular risk for future translational work.

\section{Locating and reversing ASD pathophysiology}

Identifying specific cells and circuits dysregulated in ASD is crucial in gene therapy design, as vectors may be targeted to specific brain regions or cell types (discussed in detail later). In particular, nascent data suggest the hippocampus, cerebellum and corpus callosum contain key pathogenic circuits [34, 46-48], whilst influential cell types include pyramidal cells, Purkinje cells and glial cells $[34,49]$. 
Recent technological advances have begun to elucidate the relationship between cell type-specific function and particular ASD endophenotypes. For example, in a RS mouse model, cre/lox-mediated deletion of MECP2 specifically from forebrain glutamatergic neurons led to a partial disease phenotype, with deficits in social behaviour and motor coordination, but preserved locomotor activity and fear-conditioned learning [50]. Meanwhile, in a TSC mouse model, chemogenetic excitation of the Right Crus I (RCrusI) region of the cerebellum - an area consistently noted to be altered in the ASD brain in neuroanatomical and neuroimaging studies [51, 52]was sufficient to specifically rescue social impairments, without rescuing repetitive or inflexible behaviours [53].

Within individual circuits, it appears that different ASD mutations may have opposing effects on synaptic function. For example, $\mathrm{TSC} 2^{+/-}$and $\mathrm{FMR} 1^{-/ y}$ knockouts appear to have opposite effects on mGluR-dependent long-term depression (LTD) in the hippocampus, whilst mice bred with both mutations balance each other out at the synaptic and behavioural levels [54]. Such data not only exemplify the heterogeneic nature of ASD but also highlight the necessity of optimal synaptic control, and are the first hint that a successful gene therapy must walk a narrow therapeutic tightrope between over- and under-stimulating synaptic transmissions.

A crucial further question is whether autistic phenotypes can be reversed or are neurodevelopmentally fixed. Remarkably, an array of studies in different monogenic ASD animal models have consistently demonstrated the potential for reversal of established neuronal dysfunction, either after pharmacological intervention or genetic reactivation of silenced alleles [55-60]. These findings imply that postnatally, indeed post-symptomatically, the genetic horse may not yet have bolted, and genetic correction via a delivered vector might be useful in treating cognitive dysfunction.

\section{Delivering gene therapies to the CNS}

If the ASD phenotype is reversible rather than neurodevelopmentally fixed, as implied by studies in monogenic animal models, then it follows that continuous genetic correction will be necessary for a sustained therapeutic effect. Currently, only viral packaging systems have combined efficient transduction with long-term gene expression in vivo [61] (although, as will be discussed later, certain ASD conditions may be amenable to non-virally delivered antisense nucleic acid therapies).

Of the viruses which can transduce post-mitotic cells, rAAVs have emerged as the principal CNS delivery candidate [62]. This is based upon their relatively low immunogenicity (compared to adenovirus and herpes simplex virus), limiting the likelihood of an encephalitic immune response, their ability to persist in episomal form, reducing their oncogenic potential (compared to retroviruses $[63,64]$ ), and their high production titres [12]. Indeed, rAAV vectors have already been used safely in a number of early clinical studies in CNS gene therapy, in disorders ranging from SMA to idiopathic Alzheimer's disease [65].

Optimising cell-specific targeting is critical in maximising the number of transduced target cells/dose and limiting off-target toxicity. There are two major ways in which the spatial dynamics of rAAV vectors can be adjusted. Firstly, the properties of the vector itself can be modified, to include a cell type-selective capsid (e.g. AAV9 is particularly neurotropic $[66,67])$ and/or promoter [68].

Secondly, the mode of delivery can be adjusted. Historically, rAAV vectors have been delivered intraparenchymally via stereotactic CNS injection, leading to high local concentrations with limited vector spread [69]. Although invasive (each injection requiring a craniotomy), such a localising method of delivery might have utility in correcting specific dysregulated ASD circuits linked to particular clinical endophenotypes, analogous to the recent improvement in motor scores seen after lentiviral vector delivery of a dopamine-producing gene therapy to the nigrostriatal pathway in Parkinson's disease [70].

However, ASD appears to involve global synaptic dysregulation and thus will require global CNS gene correction to fully reverse cognitive phenotypes [71, 72]. The discovery that rAAV9 crosses the blood-brain barrier (BBB) and globally transduces CNS neurons and glial cells [73], and the recent derivation of more efficient BBB-traversing rAAVs by targeted evolution [74], has opened up the possibility of using intravenous injection in ASD gene therapy.

It remains to be seen, however, whether side effects relating to peripheral tissue transduction, as well as the presence of neutralising circulating antibodies (antiAAV9 antibodies are present in $47 \%$ of humans), will preclude intravenous administration in various ASDs [75-77]. Changes to the viral vector nucleic acid sequence outside of the transgene-such as the inclusion of 'detargeting' sequences recognised by micro RNAs (miRNAs) expressed specifically in off-target cells [78]might circumvent the former issue, but use up highly limited space (rAAV's packaging capacity is limited to $\sim 5 \mathrm{~kb}$ [79]). The latter issue may be negotiated by the use of engineered rAAV capsids, which may have lower neutralising antibody seropravalences [80].

An alternative to systemic delivery is intrathecal administration, which potentially combines (relatively) safe administration and global CNS transduction with fewer peripheral complications, and a higher spatial resolution limiting the dose requirements. However, there are 
conflicting data regarding the ability of intrathecally delivered rAAV to efficiently transduce areas outside the spinal cord [81], as well its own ability to avoid both peripheral leakage [82] and a neutralising antibody response $[83,84]$. Of note, an intrathecal AAV9 approach has been corrective in a model of giant axonal neuropathy [85] and has progressed to a clinical trial.

\section{Gene therapy strategies in monogenic ASD Gene replacement}

In ASD disorders defined by loss of function mutations (e.g. RS, FXS, TSC), simple gene replacement may restore synaptic function [12]. Given the limitations imposed by imperfect gene delivery strategies, a key question is whether sufficient transduction of target cell types can be attained to exert phenotypic benefit.

Encouragingly, a number of studies using monogenic animal models have demonstrated behavioural improvements after rAAV-delivered gene replacement. In a RS mouse model, systemic delivery of a rAAV9-MECP2 vector sufficient for $\sim 10 \%$ CNS transduction (of principally neuronal cells) led to moderate behavioural improvements $[86,87]$. Meanwhile, at an 6-fold higher vector dose, 25\% CNS transduction resulted in marked behavioural and phenotypic improvements [88]. Finally, it was recently demonstrated that rAAV-mediated delivery of even a fragment of the MECP2 gene (lacking $\mathrm{N}$ - and $\mathrm{C}$ - terminal regions along with a central domain) led to phenotypic improvement in RS mice, potentially allowing extra room for construct modifications to aid target cell transduction and expression [89]. Similarly, substantial phenotypic improvements were seen in studies using FXS and TSC models after intra-CNS delivery of replacement genes, although none of these studies quantified CNS transduction [90-92].

Although a cause for optimism, none of the above studies evidenced total phenotypic reversal after gene replacement. Such incomplete phenotypic reversal may be secondary to insufficient CNS transduction. In RS for example, $\sim 80 \%$ gene reactivation in neuronal cells appears to be sufficient and necessary for total phenotypic reversal $[56,93]$. However, increasing the vector dose in order to increase transduction must be balanced against the risk of dose-related toxicity. This may occur secondary to off-target cell transgene expression: for example, transgene-specific liver toxicity was seen at high doses of rAAV9-MECP2 [86, 94], possibly due to MECP2's role in liver metabolism [95].

Toxicity may also occur secondary to supraphysiological expression in target cells. For example, after rAAV-mediated delivery of FMRP in FXS, toxicity developed at 2.5-fold expression above wild type [96], whilst duplication of MECP2 leads to MECP2 duplication syndrome in males [97-99]. Such toxicity may occur even at low transduction percentages due to uneven vector distribution within the CNS or, in the case of X-linked disorders in females, due to a mosaic pattern of CNS expression caused by random X-inactivation [100]. Reassuringly, a fragmented version of the MECP2 promoter appeared to limit MECP2 expression to physiological levels in both wild type and MECP $2^{\text {null/x }}$ female mice, even at vector doses leading to 25\% CNS transduction [88].

Nonetheless, further studies are required to pinpoint the optimum balance between CNS transduction and on-target toxicity in various ASD syndromes. Additionally, future gene replacement studies must better characterise the relationship between gene dose and dendritic function (which was not assessed in any of the above studies).

\section{RNA knockdown}

Gene expression can be silenced by sequence-specific knockdown of mRNA transcripts using techniques such as antisense oligonucleotides (ASOs) and short interfering RNAs (siRNAs), which use the exquisite specificity conferred by Watson-Crick base pairing to bind particular mRNA transcripts and prevent their translation (for a detailed mechanism see ref [101]). These nucleic acids are typically relatively easy to manufacture, can be modified to limit degradation and inflammation, and do not require a viral vector (although long-term expression of ASOs is possible using viral delivery of short hairpin RNAs [shRNAs]) [101, 102]. Indeed, such therapies are already being used in the treatment of SMA and in clinical trials for Huntington's disease [103, 104].

These techniques are principally useful when total or partial knockdown of a particular transcript may restore synaptic function. For example in MECP2 duplication syndrome, halving MECP2 expression was shown to restore cellular function and phenotype postnatally in a conditional MECP2-overexpressing mouse model [105]. In the same study, intraventricular delivery of ASOs (delivered at a constant rate by a pump) specifically targeting MECP2 led to widespread ASO distribution in the CNS, effective knockdown of MECP2 to nearly wild type levels, and sustained phenotypic reversal ( 10 weeks) [105].

Another strategy in which RNA silencing may be useful is in knocking down a gene which inhibits a target gene's expression, i.e. disinhibition. For example, triplication of 15q11-13 leads to a relatively common and highly penetrant type of autism linked to increased expression of UBE3A (which functions as a transcription regulator in addition to its ubiquitin ligase function) and subsequent downregulation of Cerebellin 1 Precursor (Cbln1), a synaptic organising protein, in the ventral tegmental area (VTA) [106]. Thus, knockdown of UBE3A could be used to restore sufficient Cbln1 expression in the VTA, which has already been shown to effect 
phenotypic change after cre/lox-mediated restoration in a UBE3A-triplicated mouse model [106].

Another application of this strategy could be in AS, where the long non-coding UBE3A antisense transcript (UBE3A-AST) causes imprinting of the paternal UBE3A allele, ensuring that a loss of maternal UBE3A allele function yields the AS phenotype (another example of how genetic defects in ASD may be bidirectional, with optimal gene expression in specific brain regions crucial). Indeed, a recent paper demonstrated that a single intracerebroventricular injection of a degradationresistant ASO targeting UBE3A-AST in an adult AS mouse model led to specific and sustained reductions in UBE3A-AST levels, with partial restoration $(\sim 40 \%)$ of UBE3A levels throughout the CNS [107].

Interestingly, in the same study, whilst motor deficits were restored, other behaviours-such as anxiety and repetitive behaviours-were not. A later study, using Cre-dependent UBE3A reactivation in an AS mouse model, showed a temporal dependence for specific phenotype reversal, with anxiety and repetitive behaviours requiring gene reactivation during early development, whilst motor deficits could be restored into adulthood [108]. Such temporal factors have not been thoroughly investigated in other monogenic ASDs but are clearly critical when considering the time point of useful intervention in humans.

Finally, in a similar vein to excessive gene replacement, hyper-knockdown of target RNA may lead to rebound toxicity in both target cells and off-target cells. Furthermore, both ASOs and siRNA may cause unpredictable off-target knockdown [109]. From this perspective, the requirement for regular intra-CNS administration of ASOs is a double-edged sword in ASD: whilst on the one hand, it is clearly less convenient than a once-off injection of viral vector, on the other hand, it allows for the possibility of dose uptitration and determination of an optimal therapeutic level.

\section{Gene editing}

One of the most exciting recent developments in gene therapy is the advent of easily customised sequence-specific editing techniques, such as CRISPR (clustered regularly interspaced short palindromic repeats)-Cas9, enabling either correction of a genetic mutation via non-homologous recombination (providing there is a suitable template) or gene silencing via non-homologous end-joining [110]. Such techniques would generally enable gene expression at physiological levels in target cells, negating the problems of transgene-associated toxicity seen with both gene replacement and RNA knockdown techniques.

Unfortunately, at least in vivo, gene editing techniques still remain a distant therapeutic prospect, with a wealth of technical hurdles to overcome, including how to deliver gene editing systems to target cells, how to increase the efficiency of editing, and how to avoid off-target editing [111, 112]. Still, recent work by Doudna and colleagues provides optimism in this regard, with the demonstration of greatly improved editing of post-mitotic neurons in adult mouse brains using cell-penetrating peptides tagged onto Cas9 ribonucleoprotein complexes [113].

\section{Prospects for gene therapy in polygenic ASD}

As previously mentioned, in comparison with monogenic ASD, polygenic ASD has a greater environmental component driving its phenotype [45]. In this respect, damaging, nonsynonymous postzygotic mutations in whole-exome sequences from the largest collection of trios with ASD were recently identified, with some of these genes being particularly enriched for expression in the amygdala, a key brain region for social conditioning and learning [114]. Such factors, combined with the current paucity and constructional limitations of animal models in polygenic ASD, make it a less obvious target for gene therapy.

Nonetheless, despite the bewildering array of rare genetic mutations linked to polygenic ASD, an important focus of these mutations appears to be in the regulation of synaptic function, with diverse ASD mutations potentially connecting aberrant translational inputs and outputs (Fig. 1) [34]. For example, in mice, deletion of the translational repressor Eukaryotic translation initiation factor 4E-binding protein 2 (4E-BP2) led to overexpression of the NLGN class of cell adhesion molecules [115], mutations of which have been causally linked to ASD $[46,116,117]$. Furthermore, such deletion resulted in disruption of the ratio of excitatory to inhibitory synaptic inputs, as well as an ASD behavioural phenotype, which was corrected by NLGN1 knockdown [115].

This leads to the idea that many ASD mutations might be treated by fine-tuning the expression of influential proteins acting within dynamic translational loops. The apparently fundamental role of the PI3K-AKT-mTOR pathway in various causes of monogenic ASD [118], as well as the phenotypic reversal seen using small molecule inhibitors of mTORC1 preclinically [119], suggests that this pathway may be a critical target for gene therapy in certain cases of ASD.

However, given ASD's heterogeneity, it is once again important not to focus myopically on a single pathway. Rather, instead of embarking on a 'one size fits all' therapeutic approach, the effect of any particular ASD mutation on translational output and synaptic function should be categorised, before deciding whether and how to target a particular gene or pathway. For instance, NLGN3 knockout mice demonstrate a FXS-like disruption of mGluR-dependent synaptic plasticity [120], suggesting that either FMRP overexpression 
or PI3K-AKT-mTOR pathway knockdown (given the aforementioned opposition of these two pathways) might correct this phenotype.

Finally, recent evidence has emerged of ASD behaviours caused by amino acid deficits [121, 122]. For example, homozygous dysfunction of the $\mathrm{BBB}$ solute carrier transporter 7a5 (SLC7A5) and corresponding CNS loss of branched chain amino acids (BCAAs) has been linked to ASD, which is reversible in mouse models upon intra-CNS administration of BCAAs [122]. Thus, direct protein replacement therapy might provide an important additional therapeutic avenue in certain ASD cases. It is also possible to imagine using gene therapy as an adjunct here: for example, combining systemic BCAA replacement with vector-delivered SLC7A5 targeting BBB cells.

\section{Conclusions}

Given the heritable component of ASD, gene therapy offers a promising alternative to conventional small molecule therapies. Preclinical studies over the last 5 years using animal models displaying autism-like traits have demonstrated that directly altering gene expression using rAAV-delivered transgenes can reverse the behavioural phenotype, either via gene replacement or RNA knockdown. Such studies establish proof-of-concept and set up a platform for clinical translation in various monogenic ASDs, with RS being a frontrunner in this regard.

However, major hurdles remain, not least the fact that the majority of ASD disorders, even monogenic ones, show variable penetrance, with epistatic and gene $\times$ environment interactions determining phenotype. Not only is such genetic and environmental heterogeneity inherently difficult to model, hindering clinical translation, but also in clinical trials that do go ahead, ASD subgroups that benefit from a particular treatment may be lost amongst other unsuitable subgroups. Furthermore, we still do not know whether, or in which cases, epigenetic factors may preclude reversibility in humans. Cyclically, this brings us back to the question of animal models and whether these have sufficient construct validity to actually begin to answer such questions in the first place.

A number of additional questions remain: Firstly, can vector design be optimised to the extent that intravenous delivery achieves sufficient CNS transduction without peripheral toxicity? Secondly, where is the optimum balance between CNS transduction and the risk of on-target transgene-related toxicity for each ASD syndrome? Thirdly, will demonstrations of acceptable levels of CNS toxicity hold when studies commence in larger animal models? Fourthly, is there a time point beyond which some or all autistic features lose their reversibility? Answering these questions will be key to moving ASD gene therapy into clinical trials, and perhaps one day generating a genetic treatment for ASD.

\section{Abbreviations}

AS: Angelman syndrome; ASD: Autistic spectrum disorder; ASO: Antisense oligonucleotide; BBB: Blood-brain barrier; BCAA: Branched chain amino acids; Cbln1: Cerebellin 1 precursor; CHD8: Chromodomain-helicase-DNA-binding protein 8; CNS: Central nervous system; CRISPR: Clustered regularly interspaced short palindromic repeats; DISC1: Disrupted in schizophrenia 1; FMR1: Fragile X mental retardation 1; FMRP: Fragile X mental retardation protein; FXS: Fragile X syndrome; LTD: Long-term depression; MECP2: MethylCpG-binding protein 2; mGluR: Metabotropic glutamate receptor; miRNA: MicroRNA; mTORC1: Mammalian target of rapamycin complex 1; NLGN: Neuroligin; NRXN: Neurexin; PI3K: Phosphatidylinositide 3-kinase: PSD95: Postsynaptic density protein 95; PTEN: Phosphatase and tensin homolog; rAAV: Recombinant adeno-associated virus; RCrusl: Right Crus I; RS: Rett syndrome; RTK: Receptor tyrosine kinase; SFARI: Simons Foundation Autism Research Initiative; shRNA: Short hairpin RNA; siRNA: Short interfering RNA; SLC7A5: Solute carrier transporter 7a5; SMA: Spinal muscular atrophy; TSC: Tuberous Sclerosis; TSC1: Tuberous sclerosis 1; TSC2: Tuberous sclerosis 2; UBE3A: Ubiquitin-protein ligase E3A; VTA: Ventral tegmental area

\section{Acknowledgements}

We thank Dr. C. Proukakis for interesting discussions around the subject of this review.

\section{Funding}

NDM was supported by the ERC and CDKL5 Foundation grants during the period of this work.

\section{Authors' contributions}

NDM and MB did the literature review; MB wrote the manuscript. MK assisted with the writing of the manuscript. All authors read, corrected and approved the final manuscript.

Ethics approval and consent to participate

Not applicable.

\section{Competing interests}

The authors declare that they have no competing interests.

\section{Publisher's Note}

Springer Nature remains neutral with regard to jurisdictional claims in published maps and institutional affiliations.

\section{Author details}

${ }^{1}$ Gene Therapy, Centre for Neuroinflammation and Neurodegeneration, Division of Brain Sciences, Faculty of Medicine, Imperial College London, Hammersmith Hospital Campus, W12 0NN, London, UK. Present address: The Portland Hospital, 205-209 Great Portland Street, London W1W 5AH, UK.

Received: 18 December 2017 Accepted: 7 June 2018

Published online: 20 June 2018

\section{References}

1. Christensen DL, et al. Prevalence of autism spectrum disorder among children aged 8 years - autism and developmental disabilities monitoring network, 11 sites, United States, 2010.," Morb. Mortal. Wkly. Rep. Surveill. Summ. Wash. DC 2002, vol. 63, no. 2, pp. 1-21, Mar. 2014.

2. Chahrour M, O'Roak BJ, Santini E, Samaco RC, Kleiman RJ, Manzini MC. Current perspectives in autism disorder: from genes to therapy. J. Neurosci. 2016;36(45):11402.

3. Zafeiriou DI, Ververi A, Vargiami E. Childhood autism and associated comorbidities. Brain Dev. 29(5):257-72.

4. Buescher AVS, Cidav Z, Knapp M, Mandell DS. Costs of autism spectrum disorders in the United Kingdom and the United States. JAMA Pediatr. 2014, 168(8):721-8.

5. LeClerc S, Easley D. Pharmacological therapies for autism spectrum disorder: a review. Pharm Ther. 2015;40(6):389-97.

6. Freitag CM. The genetics of autistic disorders and its clinical relevance: review of the literature. Mol Psychiatry. 2006;12(1):2-22.

7. Geschwind DH, State MW. Gene hunting in autism spectrum disorder: on the path to precision medicine. Lancet Neurol. 2015;14(11):1109-20. 
8. Careaga M, Murai T, Bauman MD. Maternal immune activation and autism spectrum disorder: from rodents to nonhuman and human primates. Biol Psychiatry. 2017;81(5):391-401.

9. Modabbernia A, Velthorst E, Reichenberg A. Environmental risk factors for autism: an evidence-based review of systematic reviews and meta-analyses. Mol. Autism. 2017;8(1):13.

10. Tordjman S, et al. Gene $\times$ Environment interactions in autism spectrum disorders: role of epigenetic mechanisms. Front Psychiatry. 2014;5:53.

11. Hopkins AL, Groom CR. The druggable genome. Nat Rev Drug Discov. 2002; 1(9):727-30.

12. Templeton NS. Gene and cell therapy: therapeutic mechanisms and strategies. 4th ed: CRC Press; 2015, Boca Raton, FL.

13. Naldini L. Gene therapy returns to centre stage. Nature. 2015;526(7573):351-60.

14. Hoy SM. Nusinersen: first global approval. Drugs. 2017;77(4):473-9.

15. Shaberman B. A retinal research nonprofit paves the way for commercializing gene therapies. Hum Gene Ther. 2017;28(12):1118-21.

16. Mendell JR, et al. Single-dose gene-replacement therapy for spinal muscular atrophy. N Engl J Med. 2017;377(18):1713-22.

17. Hampson G, Towse A, Pearson SD, Dreitlein WB, Henshall C. Gene therapy: evidence, value and affordability in the US health care system. J Comp Eff Res. 2018;7(1):15-28.

18. Sztainberg Y, Zoghbi HY. Lessons learned from studying syndromic autism spectrum disorders. Nat Neurosci. 2016;19(11):1408-17.

19. Amir RE, Van den Veyver IB, Wan M, Tran CQ, Francke U, Zoghbi HY. Rett syndrome is caused by mutations in X-linked MECP2, encoding methylCpG-binding protein 2. Nat Genet. 1999;23(2):185-8.

20. Kishino T, Lalande M, Wagstaff J. UBE3A/E6-AP mutations cause Angelman syndrome. Nat Genet. 1997;15(1):70-3.

21. Splawski I, et al. CaV1.2 calcium channel dysfunction causes a multisystem disorder including arrhythmia and autism. Cell. 119(1):19-31.

22. van Slegtenhorst $M$, et al. Identification of the tuberous sclerosis gene TSC1 on chromosome 9q34. Science. 1997:277(5327):805-8.

23. Verkerk AJ, et al. Identification of a gene (FMR-1) containing a CGG repeat coincident with a breakpoint cluster region exhibiting length variation in fragile X syndrome. Cell. 1991;65(5):905-14.

24. Yuen RKC, et al. Whole genome sequencing resource identifies 18 new candidate genes for autism spectrum disorder. Nat Neurosci. 2017;20(4):602-11.

25. De Rubeis $\mathrm{S}$, et al. Synaptic, transcriptional and chromatin genes disrupted in autism. Nature. 2014;515(7526):209-15.

26. Iossifov I, et al. The contribution of de novo coding mutations to autism spectrum disorder. Nature. 2014;515(7526):216-21.

27. lossifov I, et al. De novo gene disruptions in children on the autistic spectrum. Neuron. 2012;74(2):285-99.

28. Jiang $Y$, et al. Detection of clinically relevant genetic variants in autism spectrum disorder by whole-genome sequencing. Am J Hum Genet. 2013; 93(2):249-63.

29. Neale $\mathrm{BM}$, et al. Patterns and rates of exonic de novo mutations in autism spectrum disorders. Nature. 2012;485(7397):242-5.

30. O'Roak BJ, et al. Exome sequencing in sporadic autism spectrum disorders identifies severe de novo mutations. Nat Genet. 2011;43(6):585-9.

31. Sanders SJ, et al. De novo mutations revealed by whole-exome sequencing are strongly associated with autism. Nature. 2012;485(7397):237-41.

32. Yuen RKC, et al. Whole-genome sequencing of quartet families with autism spectrum disorder. Nat Med. 2015;21(2):185-91.

33. Zoghbi HY, Bear MF. Synaptic dysfunction in neurodevelopmental disorders associated with autism and intellectual disabilities. Cold Spring Harb. Perspect. Biol. 2012:4(3)

34. Kleijer KTE, et al. Neurobiology of autism gene products: towards pathogenesis and drug targets. Psychopharmacology. 2014;231(6):1037-62.

35. Loke YJ, Hannan AJ, Craig JM. The role of epigenetic change in autism spectrum disorders. Front Neurol. 2015;6:107.

36. Onore $C$, Careaga M, Ashwood $P$. The role of immune dysfunction in the pathophysiology of autism. Brain Behav Immun. 2012;26(3):383-92.

37. Beversdorf DQ, MISSOURI AUTISM SUMMIT CONSORTIUM. Phenotyping, etiological factors, and biomarkers: toward precision medicine in autism spectrum disorders. J Dev Behav Pediatr. 2016:37(8):659-73.

38. Berry-Kravis EM, et al. Effects of STX209 (arbaclofen) on neurobehavioral function in children and adults with fragile $X$ syndrome: a randomized, controlled, phase 2 trial. Sci. Transl. Med. 2012;4(152):152ra127.

39. Denayer T, Stöhr T, Van Roy M. Animal models in translational medicine: validation and prediction. New Horiz Transl Med. 2014;2(1):5-11.
40. Huerta M, Lord C. Diagnostic evaluation of autism spectrum disorders Pediatr Clin N Am. 2012:59(1):103-11.

41. Bekoff M. Animal Emotions: Exploring Passionate Natures: current interdisciplinary research provides compelling evidence that many animals experience such emotions as joy, fear, love, despair, and grief-we are not alone. BioScience. 2000;50(10):861-70.

42. Stafstrom CE, Benke TA. Autism and epilepsy: exploring the relationship using experimental models. Epilepsy Curr. 2015;15(4):206-10.

43. Crawley JN. Translational animal models of autism and neurodevelopmental disorders. Dialogues Clin Neurosci. 2012;14(3):293-305.

44. Hulbert SW, Jiang Y. Monogenic mouse models of autism spectrum disorders: common mechanisms and missing links. Neuroscience. 2016;321:3-23.

45. Persico AM, Napolioni V. Autism genetics. Behav Brain Res. 2013;251:95-112.

46. Kim H, Lim C-S, Kaang B-K. Neuronal mechanisms and circuits underlying repetitive behaviors in mouse models of autism spectrum disorder. Behav. Brain Funct. 2016;12(1):3.

47. D'Mello AM, Stoodley CJ. Cerebro-cerebellar circuits in autism spectrum disorder. Front Neurosci. 2015;9:408

48. Li J, et al. Integrated systems analysis reveals a molecular network underlying autism spectrum disorders. Mol. Syst. Biol. 2014;10(12):774.

49. Petrelli F, Pucci L, Bezzi P. Astrocytes and microglia and their potential link with autism spectrum disorders. Front Cell Neurosci. 2016;10:21.

50. Gemelli T, Berton O, Nelson ED, Perrotti LI, Jaenisch R, Monteggia LM. Postnatal loss of methyl-CpG binding protein 2 in the forebrain is sufficient to mediate behavioral aspects of Rett syndrome in mice. Biol Psychiatry. 2006;59(5):468-76.

51. Skefos J, et al. Regional alterations in purkinje ell density in patients with autism. PLOS ONE. 2014;9(2):e81255.

52. D'Mello AM, Crocetti D, Mostofsky SH, Stoodley CJ. Cerebellar gray matter and lobular volumes correlate with core autism symptoms. Neurolmage Clin. 2015;7:631-9.

53. Stoodley CJ, et al. Altered cerebellar connectivity in autism and cerebellarmediated rescue of autism-related behaviors in mice. Nat Neurosci. 2017; 20(12):1744-51.

54. Auerbach BD, Osterweil EK, Bear MF. Mutations causing syndromic autism define an axis of synaptic pathophysiology. Nature. 2011:480(7375):63-8.

55. Dolen $\mathrm{G}$, et al. Correction of fragile X syndrome in mice. Neuron. 2007;56(6): 955-62.

56. Guy J, Gan J, Selfridge J, Cobb S, Bird A. Reversal of neurological defects in a mouse model of Rett syndrome. Science. 2007;315(5815):1143-7.

57. Ehninger $D$, et al. Reversal of learning deficits in a Tsc $2+/-$ mouse model of tuberous sclerosis. Nat Med. 2008;14(8):843-8.

58. Dolan BM, et al. Rescue of fragile X syndrome phenotypes in Fmr 1 KO mice by the small-molecule PAK inhibitor FRAX486. Proc Natl Acad Sci U S A. 2013;110(14):5671-6.

59. Sztainberg $Y$, et al. Reversal of phenotypes in MECP2 duplication mice using genetic rescue or antisense oligonucleotides. Nature. 2015;528(7580):123-6.

60. Mei $Y$, et al. Adult restoration of Shank3 expression rescues selective autistic-like phenotypes. Nature. 2016:530(7591):481-4.

61. Choudhury SR, Hudry E, Maguire CA, Sena-Esteves M, Breakefield XO, Grandi P. Viral vectors for therapy of neurologic diseases. Small Mol. Neurol. Disord. 2017;120(Supplement C):63-80.

62. Gray SJ. Gene therapy and neurodevelopmental disorders. Neurodev. Disord. 2013;68(Supplement C):136-42.

63. Modlich $U$, et al. Insertional transformation of hematopoietic cells by selfinactivating lentiviral and gammaretroviral vectors. Mol. Ther. 1919-1928; 17(11)

64. Hacein-Bey-Abina S, et al. Insertional oncogenesis in 4 patients after retrovirus-mediated gene therapy of SCID-X1. J Clin Invest. 2008;118(9): 3132-42.

65. Hocquemiller M, Giersch L, Audrain M, Parker S, Cartier N. Adeno-associated virus-based gene therapy for CNS diseases. Hum Gene Ther. 2016;27(7):478-96.

66. Taymans J-M, et al. Comparative analysis of adeno-associated viral vector serotypes 1, 2, 5, 7, and 8 in mouse brain. Hum Gene Ther. 2007;18(3):195-206.

67. Aschauer DF, Kreuz S, Rumpel S. Analysis of transduction efficiency, tropism and axonal transport of AAV serotypes 1, 2, 5, 6, 8 and 9 in the mouse brain. PLOS ONE. 2013:8(9):e76310.

68. Powell SK, Rivera-Soto R, Gray SJ. Viral expression cassette elements to enhance transgene target specificity and expression in gene therapy. Discov Med. 2015;19(102):49-57. 
69. Vite $\mathrm{CH}$, Passini MA, Haskins ME, Wolfe $\mathrm{JH}$. Adeno-associated virus vectormediated transduction in the cat brain. Gene Ther. 2003;10(22):1874-81.

70. S. Palfi et al., "Long-term safety and tolerability of ProSavin, a lentiviral vector-based gene therapy for Parkinson's disease: a dose escalation, openlabel, phase 1/2 trial," The Lancet, 383, 9923, 1138-1146. 2014

71. Katz DM, et al. Rett syndrome: crossing the threshold to clinical translation. Trends Neurosci. 39(2):100-13.

72. Bruno JL, Hosseini SMH, Saggar M, Quintin E-M, Raman MM, Reiss AL. Altered brain network segregation in fragile $X$ syndrome revealed by structural connectomics. Cereb Cortex. 2017;27(3):2249-59.

73. Dehay B, Dalkara D, Dovero S, Li Q, Bezard E. Systemic scAAV9 variant mediates brain transduction in newborn rhesus macaques. 2012;2:253.

74. Deverman BE, et al. Cre-dependent selection yields AAV variants for widespread gene transfer to the adult brain. Nat Biotech. 2016;34(2):204-9.

75. Boutin $\mathrm{S}$, et al. Prevalence of serum $\lg \mathrm{G}$ and neutralizing factors against adeno-associated virus (AAV) types 1, 2, 5, 6, 8, and 9 in the healthy population: implications for gene therapy using AAV vectors. Hum Gene Ther. 2010;21(6):704-12.

76. Gray SJ, Matagne V, Bachaboina L, Yadav S, Ojeda SR, Samulski RJ. Preclinical differences of intravascular AAV9 delivery to neurons and glia: a comparative study of adult mice and nonhuman primates. Mol. Ther. 19(6):1058-69.

77. Mingozzi F, High KA. Immune responses to AAV vectors: overcoming barriers to successful gene therapy. Blood. 2013;122(1):23-36.

78. Geisler A, Fechner H. MicroRNA-regulated viral vectors for gene therapy. World J Exp Med. 2016;6(2):37-54.

79. Grieger JC, Samulski RJ. Packaging capacity of adeno-associated virus serotypes: impact of larger genomes on infectivity and postentry steps. J Virol. 2005;79(15):9933-44.

80. Tse LV, et al. Structure-guided evolution of antigenically distinct adenoassociated virus variants for immune evasion. Proc Natl Acad Sci. 2017; 114(24):E4812-21.

81. Federici $T$, et al. Robust spinal motor neuron transduction following intrathecal delivery of AAV9 in pigs. Gene Ther. 2012;19(8):852-9.

82. Schuster DJ, et al. Biodistribution of adeno-associated virus serotype 9 (AAV9) vector after intrathecal and intravenous delivery in mouse. Front Neuroanat. 2014;8:42

83. Samaranch $L$, et al. Adeno-associated virus serotype 9 transduction in the central nervous system of nonhuman primates. Hum Gene Ther. 2012;23(4):382-9.

84. Saraiva J, Nobre RJ, Pereira de Almeida L. Gene therapy for the CNS using AAVs: the impact of systemic delivery by AAV9. J. Controlled Release. 2016; 241(Supplement C):94-109.

85. Mussche $\mathrm{S}$, et al. Restoration of cytoskeleton homeostasis after gigaxonin gene transfer for giant axonal neuropathy. Hum Gene Ther. 2013;24(2):209-19.

86. Gadalla KK, et al. Improved survival and reduced phenotypic severity following AAV9/MECP2 gene transfer to neonatal and juvenile male Mecp2 knockout mice. Mol Ther. 2013;21(1):18-30.

87. Matagne $\mathrm{V}$, et al. A codon-optimized Mecp2 transgene corrects breathing deficits and improves survival in a mouse model of Rett syndrome. Neurobiol Dis. 2017:99:1-11.

88. Garg SK, et al. Systemic delivery of MeCP2 rescues behavioral and cellular deficits in female mouse models of Rett syndrome. J. Neurosci. 2013;33(34):13612.

89. Tillotson $\mathrm{R}$, et al. Radically truncated MeCP2 rescues Rett syndrome-like neurological defects. Nature. 2017:550:398

90. Zeier Z, Kumar A, Bodhinathan K, Feller JA, Foster TC, Bloom DC. Fragile X mental retardation protein replacement restores hippocampal synaptic function in a mouse model of fragile X syndrome. Gene Ther. 2009;16(9):1122-9.

91. Gholizadeh S, Arsenault J, Xuan ICY, Pacey LK, Hampson DR. Reduced phenotypic severity following adeno-associated virus-mediated Fmr1 gene delivery in fragile $X$ mice. Neuropsychopharmacol Off Publ Am Coll Neuropsychopharmacol. 2014;39(13):3100-11.

92. Prabhakar $\mathrm{S}$, et al. Survival benefit and phenotypic improvement by hamartin gene therapy in a tuberous sclerosis mouse brain model. Neurobiol Dis. 2015;82:22-31.

93. Robinson $\mathrm{L}$, et al. Morphological and functional reversal of phenotypes in a mouse model of Rett syndrome. Brain. 2012;135(9):2699-710.

94. Gadalla KK, et al. Development of a novel AAV gene therapy cassette with improved safety features and efficacy in a mouse model of Rett syndrome. Mol Ther Methods Clin Dev. 2017;5:180-90.

95. Kyle SM, Saha PK, Brown HM, Chan LC, Justice MJ. MeCP2 co-ordinates liver lipid metabolism with the NCoR1/HDAC3 corepressor complex. Hum Mol Genet. 2016;25(14):3029-41.
96. Arsenault J, et al. FMRP expression levels in mouse central nervous system neurons determine behavioral phenotype. Hum Gene Ther. 2016;27(12):982-96.

97. Friez MJ, et al. Recurrent infections, hypotonia, and mental retardation caused by duplication of MECP2 and adjacent region in Xq28. Pediatrics. 2006;118(6):e1687

98. Meins $\mathrm{M}$, et al. Submicroscopic duplication in $\mathrm{Xq} 28$ causes increased expression of the MECP2 gene in a boy with severe mental retardation and features of Rett syndrome. J Med Genet. 2005;42(2):e12.

99. Van Esch $\mathrm{H}$, et al. Duplication of the MECP2 region is a frequent cause of severe mental retardation and progressive neurological symptoms in males. Am J Hum Genet. 2005;77(3):442-53.

100. Lyon MF. X-chromosome inactivation and human genetic disease. Acta Paediatr Oslo Nor 1992 Suppl. 2002;91(439):107-12.

101. Kole R, Krainer AR, Altman S. RNA therapeutics: beyond RNA interference and antisense oligonucleotides. Nat Rev Drug Discov. 2012;11(2):125-40.

102. Wittrup A, Lieberman J. Knocking down disease: a progress report on siRNA therapeutics. Nat Rev Genet. 2015:16(9):543-52.

103. Scoto M, Finkel RS, Mercuri E, Muntoni F. Therapeutic approaches for spinal muscular atrophy (SMA). Gene Ther. 2017;24(9):514-9.

104. Wild EJ, Tabrizi SJ. Therapies targeting DNA and RNA in Huntington's disease. Lancet Neurol. 16, 10:837-47.

105. Sztainberg $Y$, et al. Reversal of phenotypes in MECP2 duplication mice using genetic rescue or antisense oligos. Nature. 2015;528(7580):123-6.

106. Krishnan $V$, et al. Autism gene Ube3a and seizures impair sociability by repressing VTA Cbln1. Nature. 2017;543(7646):507-12.

107. Meng L, Ward AJ, Chun S, Bennett CF, Beaudet AL, Rigo F. Towards a therapy for Angelman syndrome by reduction of a long non-coding RNA. Nature. 2015;518(7539):409-12.

108. Silva-Santos S, et al. Ube3a reinstatement identifies distinct developmental windows in a murine Angelman syndrome model. J Clin Invest. 2015;125(5):2069-76.

109. Watts JK, Corey DR. Gene silencing by siRNAs and antisense oligonucleotides in the laboratory and the clinic. J Pathol. 2012;226(2):365-79.

110. Maeder ML, Gersbach CA. Genome-editing technologies for gene and cel therapy. Mol Ther. 2016:24(3):430-46.

111. Peng R, Lin G, Li J. Potential pitfalls of CRISPR/Cas9-mediated genome editing. FEBS J. 2016:283(7):1218-31.

112. Wang $L$, et al. In vivo delivery systems for therapeutic genome editing. Int J Mol Sci. 2016;17(5):626

113. Staahl BT, et al. Efficient genome editing in the mouse brain by local delivery of engineered Cas9 ribonucleoprotein complexes. Nat Biotech. 2017;35(5):431-4.

114. Lim ET, et al. Rates, distribution and implications of postzygotic mosaic mutations in autism spectrum disorder. Nat Neurosci. 2017:20:1217.

115. Gkogkas CG, et al. Autism-related deficits via dysregulated elF4E-dependent translational control. Nature. 2013:493(7432):371-7.

116. Südhof TC. Neuroligins and neurexins link synaptic function to cognitive disease. Nature. 2008:455(7215):903-11.

117. Singh SK, Eroglu C. Neuroligins provide molecular links between syndromic and nonsyndromic autism. Sci Signal. 2013:6(283):re4.

118. Sato A. mTOR, a potential target to treat autism spectrum disorder. CNS Neurol Disord Drug Targets. 2016;15(5):533-43.

119. Sato A, et al. "Rapamycin reverses impaired social interaction in mouse models of tuberous sclerosis complex," Nat Commun. 2012:3:1292.

120. Baudouin SJ, et al. Shared synaptic pathophysiology in syndromic and nonsyndromic rodent models of autism. Science. 2012;338(6103):128-32

121. Novarino G, et al. Mutations in BCKD-kinase lead to a potentially treatable form of autism with epilepsy. Science. 2012;338(6105):394-7.

122. Tarlungeanu DC, et al. Impaired amino acid transport at the blood brain barrier is a cause of autism spectrum disorder. Cell. 2016;167(6):1481-1494.e18.

123. Sethna F, Moon C, Wang H. From FMRP function to potential therapies for fragile X syndrome. Neurochem Res. 2014;39(6):1016-31.

124. Richards C, Jones C, Groves L, Moss J, Oliver C. Prevalence of autism spectrum disorder phenomenology in genetic disorders: a systematic review and meta-analysis. Lancet Psychiatry. 2015:2(10):909-16.

125. Guy J, Cheval H, Selfridge J, Bird A. The role of MeCP2 in the brain. Annu Rev Cell Dev Biol. 2011:27(1):631-52.

126. Ramocki MB, et al. Autism and other neuropsychiatric symptoms are prevalent in individuals with MECP2 duplication syndrome. Ann Neurol. 2009;66(6):771-82.

127. Tee AR, Fingar DC, Manning BD, Kwiatkowski DJ, Cantley LC, Blenis J. Tuberous sclerosis complex-1 and -2 gene products function together to 
inhibit mammalian target of rapamycin (mTOR)-mediated downstream signaling. Proc Natl Acad Sci. 2002;99(21):13571-6.

128. Tomaic V, Banks L. Angelman syndrome-associated ubiquitin ligase UBE3A/ E6AP mutants interfere with the proteolytic activity of the proteasome. Cell Death Dis. 2015;6:e1625.

129. Betancur C, Sakurai T, Buxbaum JD. The emerging role of synaptic celladhesion pathways in the pathogenesis of autism spectrum disorders. Trends Neurosci. 32(7):402-12.

130. Ye H, Liu J, Wu JY. Cell adhesion molecules and their involvement in autism spectrum disorder. Neurosignals. 2010;18(2):62-71.

131. Ting JT, Peça J, Feng G. Functional consequences of mutations in postsynaptic scaffolding proteins and relevance to psychiatric disorders. Annu Rev Neurosci. 2012;35(1):49-71.

132. Zheng $F$, et al. Evidence for association between Disrupted-in-schizophrenia 1 (DISC1) gene polymorphisms and autism in Chinese Han population: a family-based association study. Behav. Brain Funct. 2011;7(1):14.

133. Chen J, Yu S, Fu Y, Li X. Synaptic proteins and receptors defects in autism spectrum disorders. Front Cell Neurosci. 2014;8:276.

134. Rojas DC. The role of glutamate and its receptors in autism and the use of glutamate receptor antagonists in treatment. J Neural Transm Vienna Austria 1996. 2014;121(8):891-905.

135. Platt RJ, et al. Chd8 mutation leads to autistic-like behaviors and impaired striatal circuits. Cell Rep. 19(2):335-50.

136. Breuss MW, Gleeson JG. When size matters: CHD8 in autism. Nat Neurosci. 2016;19(11):1430-2.

\section{Ready to submit your research? Choose BMC and benefit from:}

- fast, convenient online submission

- thorough peer review by experienced researchers in your field

- rapid publication on acceptance

- support for research data, including large and complex data types

- gold Open Access which fosters wider collaboration and increased citations

- maximum visibility for your research: over $100 \mathrm{M}$ website views per year

At BMC, research is always in progress.

Learn more biomedcentral.com/submissions 